\title{
Translating Chinese Place Names into English: The Case of Lin Yutang's Version of Fusheng Liuji
}

\author{
Shuangchang Cui \\ School of Foreign Languages, Zhejiang University of Finance and Economics, Hangzhou, China \\ Baorong Wang (Corresponding author) \\ School of Foreign Languages, Zhejiang University of Finance and Economics, Hangzhou, China
}

Received: 19-12-2015

doi:10.7575/aiac.ijclts.v.4n.2p.24
Accepted: 22-01-2016

Published: 01-04-2016

URL: http://dx.doi.org/10.7575/aiac.ijclts.v.4n.2p.24

This research work is supported by PRC's National Fund for Research in Social Sciences, the project (No. 15BYY034) being entitled "Fanyi Shehuixue Shiyu xia Zhongguo Xiandangdai Xiaoshuo Yijie Moshi Yanjiu” (Translating Modern Chinese Fiction in the Light of Sociology of Translation), and by the Ministry of Education's Research Fund, the project (No. 14YJA740032) being entitled "Fanyi Shehuixue Shiyu xia Zhongguo Xiandangdai Xiaoshuo Yijie Moshi Jiqi Yunzuo Jizhi Yanjiu”" (Translating Modern Chinese Fiction: A Sociological Study of Production Modes and Working Mechanisms).

\begin{abstract}
Chapter Four of Fusheng Liuji (Six Chapters of a Floating Life), a unique autobiographical prose work by early Qingdynasty author Shen Fu (1763-1825), records Shen's travel to many parts of the country and contains a multitude of place names, whose rich cultural connotations pose a great challenge to the translator. Drawing on Javier Franco Aixelá's taxonomy of translation strategies for treating culture-specific items, this paper attempts to describe the translation strategies adopted by world-renowned writer and translator Lin Yutang to handle these place names. An analysis of twenty-four examples indicates that Lin tended to preserve Chinese culture carried by the place names through employing cultural conservation strategies, including linguistic translation, transliteration, transliteration plus linguistic translation, transliteration plus annotation, and linguistic translation plus annotation. Furthermore, Lin occasionally resorted to such cultural substitution strategies as absolute universalization and domestication. It is concluded that on the whole Lin adopted a source-oriented approach to translation when working on Shen Fu's work. This study sheds fresh light on Lin's selection of translation strategies in the early years of his lifelong career as "a native interpreter of Chinese culture for Western readers".
\end{abstract}

Keywords: Place Names, Chinese Culture, Lin Yutang, Translation Strategies

\section{Introduction}

Fusheng Liuji (浮生六记), entitled Six Chapters of a Floating Life in Lin Yutang's English version, is an autobiographical prose work written by Shen Fu (沈复), a native of Suzhou in Jiangsu Province. Shen had remained virtually obscure before Lin rendered his memoir into fluent and elegant English in the mid-1930s. The book originally contained six chapters, but for some reasons the last two chapters were lost, with only four chapters left. They are "Wedded Bliss", "The Little Pleasure of Life", "Sorrow", and "The Joys of Travel" (Shen Fu, 1999). According to Lin Yutang, its Chinese title refers to two lines in a poem by great Tang poet Li Bai: "Our floating life is like a dream; how often can one enjoy oneself?" "In form, it is unique, an autobiographical story mixed with observations and comments on the art of living, the little pleasures of life, some vivid sketches of scenery and literary and art criticism" (Lin, 1999a: 23). The author's courage and sincerity preserve his book marked with charm and pathos from mere sentimentality and lend it a sort of greatness, hence is recognized as a "minor classic" in Chinese literature (Trewin \& Hawkes, 1961: 26).

Lin's translation, completed in the summer and fall of 1935, was initially serialized in two Shanghai-based Englishlanguage magazines T'ien Hsia Monthly (天下月刊) and Hsi Feng Monthly (西风月刊). At the time of its serialized publication, "some British readers were reportedly so touched by the story that they could not finish reading it, attesting to the fact that the little book was very popular back then" (Lin, 1999b: 330). ${ }^{1}$ In May 1939, Lin's translations were collected in a single volume published by the Shanghai-based Hsi Feng Press in Chinese-English edition. "As of March 1949, the bilingual edition had been reprinted seven times" (Qin \& Wu, 2013: 21). And according to Lu (2010: 50, Note 6), "this bilingual edition not only introduced Shen Fu's memoir to English readers living in China, but also increased its popularity among Chinese readers", given the fact that by the early 1940s the Chinese version of Fusheng Liuji had been reprinted as many as fifty times. Sixty years after its initial publication in book form, the bilingual edition was reprinted in 1999 by the Beijing-based Foreign Language Teaching and Research Press. The "Publisher's Note" says, "Lin's translation has been chosen for reprinting not only to acknowledge his remarkable contribution to introducing Chinese culture to the West, but also because Six Chapters of a Floating Life represents his most masterful 
translation from the Chinese" (Shen Fu, 1999: 1). While the Xi Feng edition was primarily aimed at English readers living then in China and Chinese readers knowing English, the Western reader, according to Trewin \& Hawkes (1961: 26), got to know Shen's work in two of Lin's books: first in The Importance of Living (1937: 288-292), which contains translations of several passages, and then again in The Wisdom of China and India (1942: 964-1050) which contains a nearly complete translation.

Lin Yutang (林语堂, 1895-1976), who is commonly recognized as standing “astride the cultures of East and West”, is a world-renowned modern Chinese bilingual writer, translator and cultural critic. He is best known in the West for such bestsellers as My Country and My People (1935), The Importance of Living (1937), and Moment in Peking (1939). "In terms of his status as a native interpreter of Chinese culture for Western readers, Lin's influence and authority was unmatched during the first half the twentieth century" (Williams, 2010: 390). Shen Fu's Fusheng Liuji marks the beginning of his lifelong career as "an interpreter of Chinese culture for Western readers". Hence, over the past years there has been a keen scholarly interest in Lin's translation of Fusheng Liuji (see Wen \& Deng, 2012).

Chapter Four of Shen Fu's memoir, "The Joys of Travel” in Lin's translation, records the author's travel experiences in most parts of the country. Hence, it contains a multitude of place names, including those of famous Chinese scenic spots and historic buildings, whose rich cultural connotations often pose a great challenge to the translator. How did Lin treat these Chinese culture-specific place names? Which translation strategies were employed? Did Lin try to retain the cultural information expressed in the place name or substitute such information with English equivalents? Or did he try to neutralize such cultural information? According to Yang \& Zhou (2009), Lin's translation techniques are limited only to transliteration, literal translation and paraphrase. Li (2007: 55) observes that "for the most part Lin tried to foreignize Chinese culture-specific words to represent the essence of the original work", while Wang (2004: 105) notes that in most cases Lin resorted to transliteration based on the Wade-Giles Romanization system, "causing the complete loss of the cultural connotations of the place names".

Such findings are all based on analysis of Lin's translation of several place names in the original work. Yet our examination of twenty-four place names in Chapter Four and Lin's renderings yields more interesting and nuanced findings. Adopting the descriptive model developed by Toury (1995) and drawing on Aixelá's taxonomy of translation strategies for treating culture-specific items, this paper aims to describe the translation strategies which Lin Yutang adopted to handle the place names in "The Joys of Travel".

\section{Place Names in "The Joys of Travel" and the Translation Problem}

Shen Fu was born in 1763. "The country was then in the heyday of peace and, moreover, I was born in a scholars' family, living by the side of the Ts'anglang Pavilion in Soochow" (Shen Fu, 1999: 2-3). ${ }^{2}$ Hence, many famous spots in Soochow (Suzhou), best known for its classical gardens, are recorded in his memoir. Spending most of his life as a secretary to magistrates, Shen Fu traveled widely throughout the country. At the outset of Chapter Four, Shen claimed, "For thirty years I worked as a government clerk in different yamen and practically visited every province except Szechuen, Kweichow and Yunnan" (Shen Fu, 1999: 198). "The Joys of Travel" not only gives vivid sketches of scenery of various places the author visited, but also records anecdotes, local customs and historical allusions related to these places. Most place names in Chapter Four can be classified into four groups:

(a) Geographical names, e.g. “山阴” (Shanyin), “杭州” (Hangchow), “苏州” (Soochow).

(b) Names of scenic spots, e.g. “西湖” (the West Lake, a well-known tourist attraction in Hangzhou, “飞来峰” (the Flying Peak, one of the highlights of the West Lake).

(c) Names of historic buildings, e.g. “寒山寺” (the Hanshan Temple in Soochow), “滕王阁” (the Tower of Prince T’eng in Nanchang, Jiangxi Province).

(d) Place names alluding to historical events or figures, e.g. "兰亭” (the Orchid Pavilion) in Shaoxing relating to the celebrated Eastern Jin calligrapher Wang Hsichih (Wang Xizhi, 303-361 AD); “邓尉山” (The Tengwei Hill) lying in the suburbs of Suzhou thus named in memory of Teng Wei, a military strategist in Han Dynasty (206 BC-220 AD).

Of the above four groups, geographical names, generally marked by their denotative meanings, can often be safely transliterated while the other three categories of place names, most of which carry rich connotative meaning or cultural information, cannot be simply transliterated without the loss of much cultural sense. Obviously, English readers will not be able to appreciate the novel fully if they do not understand the denotative and connotative meanings of such place names. Unfortunately, due to the geographical and historical remoteness between China and the West, the general English reader often knows nothing about the cultural information carried by these place names. Yet the translator cannot save his trouble by explaining all the cultural information with footnotes, which can divert the reader' attention away from the text and disrupt the flow of the reading process. Consequently, these place names pose a special challenge to the translator.

\section{Aixelá's Taxonomy of Translation Strategies for Culture-Specific Items}

The notion "culture-specific item" (CSI) is defined as

any linguistically represented reference in a source text which, when transferred to a target language, poses a translation problem due to the nonexistence or to the different value (whether determined by ideology, usage, frequency, etc.) of the given item in the target language culture (Aixelá, 1996: 57). 
In a narrower sense, culture-specific items refer to "those items especially linked to the most arbitrary area of each linguistic system - its local institutions, streets, historical figures, place names, personal names, periodicals, works of art, etc. - which will normally present a translation problem in other languages" (Aixelá, 1996: 57). Judging by definition, Aixelá's notion of "culture-specific item" and taxonomy of translation strategies for treating such items serve as a valid analytical tool for this study of place names in a Chinese literary text.

Through translation data collection and analysis, Aixelá was able to gather "all possible strategies applied to CSIs in translation" which are divided into two major groups separated by their conservative or substitutive nature, i.e. "by the conservation or substitution of the original reference(s) by other(s) closer to the receiving pole" (Aixelá, 1996: 60-61).

Cultural conservation strategies include the following translation procedures (Aixelá, 1996: 61-62): ${ }^{3}$

1) Repetition: "The translators keep as much as they can of the original reference". 4

2)Orthographic adaptation: "This strategy includes procedures like transcription and transliteration, which are mainly used when the original reference is expressed in a different alphabet from the one target readers use". 5

3) Linguistic (non-cultural) translation: "The translator chooses in many cases a denotatively very close reference to the original, but increases its comprehensibility by offering a target language version which can still be recognized as belonging to the cultural system of the source text". (By definition this procedure is similar to what is commonly known as "literal translation").

4) Extratextual gloss: "The translator uses one of the above-mentioned procedures, but considers it necessary to offer some explanation of the meaning or implications of the CSI", often in the form of footnote, endnote, glossary, commentary in brackets or italics.

5) Intratextual gloss: "the translators feel they can or should include their gloss as an indistinct part of the text, usually so as not to disturb the reader's attention".

Cultural substitution strategies include the following translation procedures (Aixelá, 1996: 63-64):

6) Synonymy: "The translator resorts to some kind of synonym or parallel reference to avoid repeating the CSI".

7) Limited universalization: the translator chooses another source culture reference which is less culture-specific than the original CSI and therefore more familiar to the target readers (e.g. "American football" is rendered as "a ball of rugby").

8) Absolute universalization: "translators do not find a better known CSI or prefer to delete any foreign connotations and choose a neutral reference for their readers" (e.g. "Chesterfield", i.e. a large sofa often covered in leather, is neutralized as "sofa").

9) Naturalization: "The translator decides to bring the CSI into the intertextual corpus felt as specific by the target language culture". 6

10) Deletion: the original CSI is deleted in the translation where "the translators consider the CSI unacceptable on ideological or stylistic grounds, or they think that it is not relevant enough for the effort of comprehension required of their readers, or that it is too obscure and they are not allowed or do not want to use procedures such as the gloss".

11) Autonomous creation: To insert in the target text a nonexistent cultural reference in the source text”.

Finally, according to Aixelá (1996: 60), "these translation procedures can be combined -- and in fact often are combined" in real-life translation, e.g. the use of gloss to aid a major translation procedure, say, linguistic translation.

\section{Lin's Translation Strategies for Place Names}

Our sample analysis of twenty-four place names and Lin's translations, roughly one third of the total in Chapter Four, reveals that on the whole Lin tended to retain Chinese culture contained in the place names during the translation process. Consequently, in most cases he employed cultural conservation strategies while resorting to substitution ones where he found a particular place name too pregnant with cultural connotations to be fully preserved in the translation or not significant enough in the original work to be worthy of being preserved. Moreover, such substitution techniques as synonymy, limited universalization, deletion and autonomous creation were not employed by Lin. Below is a detailed analysis of seven translation procedures observed in Lin's renderings of these twenty-four place names.

\subsection{Cultural Conservation Strategies}

\subsubsection{Transliteration}

Transliteration was frequently employed by Lin Yutang primarily to deal with geographical names in Chapter Four. Yet occasionally it was also employed to treat place names of the other three categories. For example:

ST-1: 余游幕三十年来，天下所未到者，蜀中，黔中与滇南耳。(Shen Fu, 1999: 198)

(Yu youmu sanshinian lai, tianxia suo weidao zhe, Shuzhong, Qianzhong yu Diannan er.)

TT-1: For thirty years I worked as a government clerk in different yamen and practically visited every province except Szechuen, Kweichow and Yunnan. (p. 199)

ST-2: 至海宁，与白门史心月，山阴俞午桥同事。(p. 232)

(Zhi Haining, yu Baimen Shi Xinyue, Shanyin Yu Wuqiao tongshi.) 
TT-2: At Haining I was working with Shih Hsinyueh of Pomen [Nanking] and Yu Wuch'iao of Shanyin as my colleagues. (p. 233)

ST-3: 迨居萧爽楼，正作烟火神仙。(p. 244)

(Dai ju Xiaoshuang Lou, zheng zuo yanhuo shenxian.)

TT-3: Afterwards we were staying at the Hsiaoshuanglou, living like fairies on earth. (p. 245)

All the geographical names in Examples 1 and 2 are transliterated presumably because they contain no special meanings or cultural connotations. However, it is not the same case with “萧爽楼” (Xiaoshuang Lou), which means literally “the Tower of Refreshing Winds" and is not a geographical name. Needless to say, its denotative meaning is significant enough to be translated for the English reader. Yet “萧爽楼” was also transliterated by Lin, including even the category word “楼” (tower) in it, probably because only the name itself is mentioned by the author, without describing its geographical location or view. In other words, Lin deemed it not important enough to merit a more creative rendering. This example indicates that Lin translated place names resourcefully and flexibly according to their relative importance in the original work.

\subsubsection{Linguistic (Non-Cultural) Translation}

Linguistic translation serves to convey the denotative meaning of the original CSI without trying to transfer to the target language its connotative or cultural meaning, hence is also called "non-cultural translation". Our data of translation examples reveals that Lin employed it more frequently than transliteration to translate those place names other than geographical ones. Obviously, linguistic translation, which is roughly equivalent to literal translation, is most convenient for the translator next only to transliteration. For example:

ST-4:

其红门局之梅花，姑姑庙之铁树，不过尔尔。紫阳洞予以为必可观，而访寻得之，洞口仅容一指，涓涓流 水而已。( p. 206)

(Qi Hongmen Ju zhi meihua, Gugu Miao zhi tieshu, buguo erer. Ziyang Dong yu yiwei bi keguan, er fangxun dezhi, dongkou jin rong yi zhi, juanjuan liushui eryi.)

TT-4: The plum-blossoms of the Red Gate Ground and the ironwood trees of the Kuku Temple were, in fact, not much to look at. The Purple Sun Cave, which we had thought worth seeing and took some trouble to reach, proved to be merely a spring with water flowing down from a hole, the "entrance to the cave," which was but the size of a finger. (p. 207)

“红门局” (Hongmen $J u$, literally “Red Gate Bureau”) refers to the imperial government-run weaving bureau located in Hangzhou, Zhejiang Province. The silk and satin produced here were exclusively supplied to the imperial families during the Ming (1368-1644 AD) and Qing Dynasties (1644-1912 AD). Originally called "the North Bureau", the weaving institution was thus named for its majestic red-lacquered gates.7 “紫阳洞” (Ziyang Dong), lying on Ziyang Hill in the western suburbs of Hangzhou, alludes to a Taoist immortal by the name of Ziyang (983-1082 AD), a native of Zhejiang. ${ }^{8}$ Lin Yutang brought out for the English reader only the denotative meaning of “红门局” and “紫阳洞”, presumably because he decided that they did not deserve a lengthy gloss to explain their historical background or cultural information. And it should be noted that "Ground" in Lin's translation is not a proper word and can be revised as "Weaving Bureau". Below is another example:

ST-5:

城尽以虹园为首折而向北，有石梁曰“虹桥”。不知园以桥名乎? 桥以园名乎? 荡舟过，日“长堤春柳”。(p. 222)

(Cheng jin yi Hongyuan weishou zhe er xiangbei, you shiliang yue "Hongqiao". Buzhi yuan yi qiao ming hu? Qiao yi yuan ming hu? Dangzhou guo, yue "Changdi Chunliu”.)

TT-5: The stretch began with the Rainbow Garden immediately adjoining the city wall, and after a turn to the north, came the Rainbow Bridge: I do not know whether the garden took its name from the bridge or the bridge from the garden. Rowing past these places, one came to the scene called "Spring Willows on a Long Embankment." (p. 223)

“长堤春柳” (Changdi Chunliu) is one of the 24 famous scenes in Yangchow (Yangzhou), Jiangsu Province. Here, Lin also resorted to linguistic translation to convey the denotative meaning ("Spring Willows on a Long Embankment") of this beautiful Chinese scene to English readers. In the same way, “虹园” (Hongyuan) and “虹桥” (Hongqiao) are rendered literally as "the Rainbow Garden" and "the Rainbow Bridge" respectively. Yet in this case, it seems to us that Lin was rightly justified to translate literally because the three names of natural scenery are not pregnant with cultural connotations and therefore linguistic translation would serve the purpose.

\subsubsection{Transliteration Plus Linguistic Translation}

A large number of place names in Chapter Four consist of two parts: a proper noun and a category word, e.g. “武林门” (Wulin Gate) in Hangzhou, “寒山寺” (Hanshan Temple) in Suzhou. As a rule, Lin would Romanize the proper noun (e.g. Wulin, Hanshan) into Wade-Giles while treating the category word with a linguistic translation (e.g. Gate, Temple). This combined procedure can partly remedy the shortcomings of transliteration by which the denotative meaning of a place name cannot be brought out to the English reader. For example: 
ST-6: 时值长夏，起极早，出钱塘门，过昭庆寺，上断桥，坐石阑上。(p. 204)

(Shizhi chang xia, qi ji zao, chu Qiantang Men, guo Zhaoqing Si, shang Duanqiao, zuo shilan shang.)

TT-6: It was summer then and we would get up very early, pass the Ch'ient'ang Gate and the Chaoch'ing

Temple, come down the Broken Bridge and sit down on its stone balustrade. (p. 205)

“钱塘门” (Qiantang Men), constructed during Sui Dynasty (581-618 AD), is one of Hangzhou's ten ancient city gates standing around the West Lake.9 “昭庆寺” (Zhaoqing $\mathrm{Si}$ ), a famous Buddhist temple constructed during the Five Dynasties (707-960 AD) and rebuilt in 1713 during the reign of Emperor Kangxi of Qing Dynasty, stood on the northern bank of the West Lake. ${ }^{10}$ Lin translated them by Romanizing the base part (Ch'ient'ang, Chaoch'ing) and rendering literally the category word (Gate, Temple). Obviously, the combined use of transliteration and linguistic translation helps retain the foreignness of the place name while explicating part of its denotative meaning, but the rich cultural information contained therein remains largely not transmitted to the English reader.

ST-7:

越日天将晓，鸿干已登门相邀，逐携榼出胥门，入面作，各饱食。渡胥江，步至横塘柊市桥，雇一叶扁舟

到山，日犹未午。(p. 214)

(Yue ri tian jiang xiao, Honggan yi dengmen xiangyao, sui xie ke chu Xumen, ru miansi, ge baoshi. Du Xujiang, bu zhi Hengtang Zaoshi Qiao, gu yiye bianzhou dao shan, ri you wei yu.)

TT-7: At dawn, Hungkan appeared at my home, and we brought the case along, passed the Hsumen Gate, and went into a noodle shop to have our breakfast. Then we crossed the Hsukiang River and walked by foot to the Date-Market Bridge at Hengt'ang. From there we engaged a boat, reaching the place shortly before noon. (p. 215)

“胥门” (Xumen) refers to the ancient city gate that once stood in the western corner of Suzhou and “胥江” (Xuiiano) to the river flowing in front of the gate. They unmistakably allude to Wu Zixu (伍子胥, 559-484 BC), a general and politician of the Wu Kingdom which made Suzhou its capital during the Spring and Autumn Period (722-481 BC). ${ }^{11}$ Combining transliteration and linguistic translation, Lin rendered them as "Hsumen Gate" and "Hsukiang River" without trying to gloss the historical figure alluded to, probably because he thought it would be too obscure to English readers.

4.1.4 Transliteration Plus Gloss

In certain cases Lin Yutang would resort to gloss to treat a Romanized place name whose denotative meaning still evades English readers. For example:

ST-8:

近山见一石洞，上有片石，横裂欲堕，即从其下荡舟入，豁然空其中，四面皆峭壁，俗名之曰水园。[…]

阁后有道通旱园，拳石乱直，[...]。(p. 200)

(Jin shan jian yi shidong, shang you pian shi, henglie yu duo, ji cong qi xia dang zhou ru, huoran kong qizhong, simian jie qiaobi, suming zhi yue "Shuiyuan". Ge hou you dao tong Hanyuan, quan shi luan chu.)

TT-8: On approaching the hill, I saw there was a stone cave with a rock jutting out horizontally as if it was going to fall down. My boat passed under this and went inside the cave, commonly known as "Shuiyüan" (Water Park), which was very spacious within and surrounded on all sides by perpendicular rocks. [...] A road led from the back of the open tower to "Hanÿ̈an" (Land Park), where there was a jumble of rockery. (p. 201)

“水园” (Shuiyuan) and “旱园” (Hanyuan) refer to two marvelous rock structures shaped after thousands of years of mountain cutting at Houshan Hill in Shaoxing, Zhejiang Province. In translating them Lin combined transliteration and a short intratextual gloss in brackets, by which the translated names retain the beauty of the original sound and convey the denotative meaning of the place names without distracting the reader's attention. Below is an example of transliteration assisted by an extratextual gloss:

ST-9: 馆江北四年，一无快游可记。(p. 242)

(Guan Jiangbei si nian, yi wu kuaiyou keji.)

TT-9: I stayed four years in Kiangpei*, during which period I did not enjoy any travel worth recording.

* A collective name given to such districts in Kiangsu as lie to the north of the Yangtze River, -- Yangchow, Icheng, Taichow, Taihing, Tsingkiang, Nantungchow, etc. being among these districts. (p. 243)

“江北” (Jiangbei), which literally means "the vast stretches of land lying to the north of the Yangtze River", actually refers to the northern areas of Jiangsu Province in this context. It was first transliterated into "Kiangpei". Yet as the general English reader still has no idea about this Romanized Chinese place, Lin added a footnote to explain its geographical location and those districts under its jurisdiction.

Taken together, Examples 8 and 9 indicate that Lin chose the kind of gloss to be used according to the relative importance of place names in the original work. He would use a short intratextual gloss for a lesser place name and a footnote for an important place name.

\subsubsection{Linguistic (Non-Cultural) Translation Plus Gloss}

Linguistic translation plus annotation was employed in such circumstances as when Lin realized that a certain place name was pregnant with cultural connotations deserving the English reader's attention and therefore a linguistic 
translation must be complemented by annotation. Annotation is generally employed to supply essential background information about the place name. For example:

ST-10: 惜乎兰亭、禹陵未能一到，至今以为憾。(p. 200)

(Xi hu Lanting Yuling weineng yi dao, zhijin yiwei han.)

TT-10: Unfortunately I was not able to visit the Orchid Pavilion* and Emperor Yu's Tomb, a sin of omission which I very much regret to this day.

* Made famous by Wang Hsichih's essay. -- Tr.) (p. 201)

“兰亭” (Lanting), a tourist attraction lying at the foot of Lanzhu Hill about thirteen kilometers southwest of Shaoxing in Zhejiang Province, won its popularity thanks to Wang Hsichih (Wang Xizhi), often referred to as the "Sage of Chinese Calligraphy", who composed the "Preface to the Poems Collected at the Orchid Pavilion" in 353 AD. Recording a grand event at which 42 literati attended a gathering at this very spot where they composed poems, played music, and enjoyed wine, Wang's preface is among the best-known and oft-copied pieces of calligraphy in Chinese history. ${ }^{12}$ In translating this place name, Lin complemented a linguistic translation ("the Orchid Pavilion") with a short footnote tracing the fame of the Orchid Pavilion to Wang and his famous essay. Yet while Lin's intentions to retain Chinese culture in his translation are unmistakably clear, the explanatory note he added involving a Chinese personal name (e.g. Wang Hsichih) is equally strange to general English readers.

ST-11: 其家在烟雨楼侧，一阁临河，曰水月居，其诵经处也，洁净如僧舍。(p. 230)

(Qi jia zai Yanyu Lou ce, yi ge linhe, yue Shuiyue Ju, qi songjing chu er, jiejing ru sengshe.)

TT-11: His home was situated by the side of the Tower of Mist and Rain [at Kashing], and had an open tower called Moon-in-the-Water Lodge overlooking the river. This was where he used to recite Buddhist books and was arranged spick and span like a monk's studio. (p. 231)

“烟雨楼” (Yanyu Lou) is a famous tourist attraction rising above the South Lake in Kashing (Jiaxing) of Zhejiang Province. The tower looks best when clouded in mist and rain, hence its poetic name. Lin rendered it as "the Tower of Mist and Rain [at Kashing]", combining linguistic translation ("the Tower of Mist and Rain") and intratextual gloss ([at Kashing]). In so doing Lin was able to inform English readers of both the distinctive features and the geographical location of the tower.

\subsection{Cultural Substitution Strategies}

As already discussed above, Lin tended to retain Chinese culture contained in the place names by employing cultural conservation strategies. However, he would resort to cultural substitution strategies where he found a particular place name too pregnant with cultural connotations to be fully preserved in the translation or too insignificant in the original work to be worthy of being preserved. In cases like this, he would either domesticate or absolutely universalize the place name.

\subsubsection{Absolute Universalization}

Some place names pregnant with abstract meanings are rather obscure to Chinese readers, not to mention general English readers. To pave the way for English readers or to save himself the trouble of providing a gloss, Lin would sacrifice the rich and complicated cultural connotations of a place name and choose a culturally neutral reference to substitute it. This translation procedure is called "absolute universalization” by Aixelá. For example:

\section{ST-12: 由寒山至高义园之白云精舍。(p. 214)}

(You Hanshan zhi Gaoyi Yuan zhi Baiyun Jingshe.)

TT-12: We then went on from the Hanshan Temple to the While Cloud Villa, by the Garden of High Virtue. (p. 215)

Standing at the southern foot of Tianping Hill in Suzhou, “高义园” (Gaoyi Yuan, “高” means “high” literally) refers to the memorial hall of Fan Zhongyan's clan. It became known as “高义园” after Emperor Qianlong of the Qing Dynasty inscribed the three Chinese characters at the site which he visited in $1751 .{ }^{13}$ Fan Zhongyan (989-1052) was a prominent politician and literary figure during Song Dynasty. He was most known for his moral uprightness and boldness in speaking out to uphold justice. His oft-quoted poetic lines, i.e. "Bear the hardship and bitterness before others; Enjoy comfort and happiness after others". "Better remonstrate and die than keep silent and live", are believed to embody the moral integrity, sound conscience, and moral responsibility required of Chinese scholar-officials. ${ }^{14}$ Yet "义” is a complicated Chinese cultural concept pregnant with multiple meanings, including loyalty, devotion, sacrifice, integrity, etc., all of which apply well to Fan Zhongyan. Obviously, its rich connotations rooted in Chinese culture cannot be found in any existing English word.

In an article written in 1932, Lin Yutang (1984: 426-427) observes that "every word has its own character; while it is possible to find in another language a word which is most approximate, a word that is perfectly equivalent in sense, coloring and character is non-existent in another language". According to Lin, translators have to admit that many words are simply "untranslatable". “高义” in Lin's eyes must be a case of untranslatability. Therefore, Lin found an English word he thought was most approximate to it -- the culturally neutral "virtue" which means "moral excellence and righteousness". Although the substitution of "virtue" for “高义” makes the text much easier for the English reader, 
much cultural significance of the Chinese notion is lost. That is perhaps the reason why Lin resorted to cultural substitution strategies occasionally.

\subsubsection{Naturalization}

By naturalization a target culture-specific item is chosen to substitute the source culture-specific one. Since "a transparent, fluent style is adopted in order to minimize the strangeness of the foreign text for TL readers" (Shuttleworth \& Cowie, 2004:43-44), the English reader will have an easy time of it reading the translation. However, as perfect correspondence in denotative, connotative and cultural meanings between Chinese and English words is the exception to the rule, naturalization often causes the loss or distortion of the cultural meaning of a place name. An illustrative example taken from Chapter One is given by Hu \& Shi (2006: 40) of Lin's naturalizing “水仙庙” (Shuixian Miao), which in the context refers to the temple to Water Immortal in charge of the Dongting Lake, as "the Narcissus Temple". Narcissus, which in Greek mythology refers to a beautiful young man who fell in love with his own reflection in the water, distorts the image of the Chinese immortal. Below are two examples of naturalization:

\section{ST-13: 石取天竺之飞来峰，城隍山之瑞石古洞。(p. 202) \\ (Shi qu Tianzhu zhi Feilai Feng, Chenghuang Shan zhi Ruishi Gudong.)}

TT-13: For rocks I would prefer the Flying Peak of T'ienchu and the Ancient Cave of Precious Stones on the City God's Hill. (p. 203)

ST-14: 桥北数武有崇文书院。(p. 204)

(Qiao bei shu wu you Chongwen Shuyuan.)

TT-14: A few paces north from the Hsiling Bridge there was the Ts'ungwen College. (p. 205)

“城隍” (Chenghuang) refers to "a Chinese mythical deity who is believed to protect a city from possible harm by evil spirits" (Dictionary of Modern Chinese, 2002: 162). Both its denotative and cultural meanings are different from "God" in Western religious faith. “书院” (Shuyuan) refers to "a privately-funded local institution, presided over by someone, where students read books and scholars gave lectures" (Dictionary of Modern Chinese, 2002: 1169). The English word "college" initially means any corporate group, and its modern sense of "academic institution" attested from the 1560s became the principal sense in the 19th century via use at Oxford and Cambridge. ${ }^{15}$ As the Chinese-styled “书院” was designed for the elite while the Western college served the masses, they have different denotative and cultural meanings. Steeped in the cultures of East and West, Lin should be well aware of the loss or distortion of the cultural meaning involved in the process of translation. Yet still he chose to domesticate “城隍” and “书院” into "city god" and "college" respectively presumably for three reasons: Lin did not see the two place names as of much significance in the original work and therefore their cultural connotations did not deserve to be fully preserved and conveyed in the translation; Lin found "city god" and "college" "most approximate" though not "perfectly equivalent" to "城隍" and “书院”; naturalized translation which helps minimizes the strangeness of Chinese place names makes reading much easier for English readers.

\section{Conclusion}

This study of Lin Yutang's rendering of place names in Fusheng Liuji leads us to the following conclusions and observations:

Firstly, place names in literary texts are significant as they are often pregnant with rich cultural information. And such culture-specific items can pose a big problem to translators chiefly because no equivalents can be found in the target language. The specific translation strategies employed by translators to handle such items can reveal their general approach to translation, i.e. whether source-oriented or target-oriented.

Secondly, Lin tended to preserve Chinese culture contained in the place names by employing cultural conservation strategies, including linguistic translation, transliteration, transliteration plus linguistic translation, transliteration plus annotation, and linguistic translation plus annotation. Transliteration was employed primarily to deal with geographical names while linguistic (non-cultural) translation was even more frequently adopted to handle those place names other than geographical ones. On the other hand, Lin would sometimes resort to cultural substitution strategies where he found a particular place name too pregnant with cultural connotations to be fully preserved or not significant enough in the original work to merit being preserved. However, such strategies were limited to naturalization and absolute universalization intended to pave the way for English readers. The other substitution techniques like synonymy, limited universalization, and deletion were not employed. Our findings demonstrate that Yang \& Zhou's (2009) observation that "Lin's translation techniques are limited only to transliteration, literal translation and paraphrase" is incorrect, and that Wang's comment that "in most cases Lin resorted to transliteration to handle place names" fails to do justice to Lin's resourcefulness and flexibility, while Li's (2007) observation that "for the most part Lin tried to foreignize Chinese culture-specific words to represent the essence of the original work" is correct, though not supported by sufficient data.

Finally, this study indicates that on the whole Lin adopted a source-oriented approach when translating Shen Fu's memoir. Where he deemed possible, he would strive for the preservation of Chinese culture by employing foreignizing translation strategies. In other word, his was a highly "faithful" version of the original. Despite his pursuit of such strategies, his translation was quite successful and warmly received by English readers living then in China. It should be noted that current scholarship on Lin's English translations of classic Chinese texts is focused on his later productions, which are generally held to show his penchant for "trans-editing" the original text. According to Huang (2013), "the 
fusion of creative writing and translating as is often found in Lin's translations" contributed greatly to the popularity of his English writings in the West. This study, therefore, sheds fresh light on Lin's adoption of alternative translation strategies in the early years of his lifelong career as "a native interpreter of Chinese culture for Western readers". And it has important implications for the Chinese government's commitment to introduce Chinese literature and culture to the outside world.

\section{References}

Aixelá, J. F. (1996). Culture-Specific Items in Translation. In R. Alvarez, \& M. C. Vidal (Eds.), Translation, Power, Subversion (pp. 52-78). Clevedon: Multilingual Matters.

Hu, X., \& Shi, Z. (2006). Lin Yutang de Fanyi Sixiang jiqi Yingyi Fusheng Liuji (On Lin Yutang's Translation Thoughts and His Translation of Fusheng Liuji). Journal of Anhui University of Science and Technology (Social Sciences Edition), (4): 35-40.

Huang, Z. (2013, May 13). Lin Yutang: Zhongguo Wenhua Yi Chu de Dianfan (Lin Yutang: The Best Exemplar of Translating Chinese Culture for the World). Guangming Daily, 05.

Li, T. (2007). Wenhua Quxiang yu Fanyi Celv: Fusheng Liuji Liangge Ying Yiben Zhi Bijiao (Cultural Orientation and Translation Strategies: Comparative Study of Two English Versions of Fusheng Liuji). Foreign Languages and Their Teaching, (7): 53-55.

Lin, Y. (1937). The Importance of Living. New York: Reynal \& Hitchcock.

Lin, Y. (1942). The Wisdom of China and India. New York: Random House.

Lin Y. (1984). Lun Fanyi (On Translation). In X. Luo (Ed.), Fanyi Lunji (Anthology of Chinese Writings on Translation) (pp. 417-432). Beijing: The Commercial Press.

Lin, Y. (1999a). Preface. In F. Shen, Six Chapters of a Floating Life (pp. 20-23). Beijing: Foreign Language Teaching and Research Press.

Lin, Y. (1999b). Houji (Translator's Postscript). In F. Shen, Six Chapters of a Floating Life (p. 330). Beijing: Foreign Language Teaching and Research Press.

Lu, F. (2010). The Afterlife of Six Chapters of a Floating Life: Three English Translations of Fusheng Liuji. Translation Review, (80): 25-52.

Qin, X. \& Wu, X. (2013). Dangdai Zuojia Yanjiu Ziliao Huibian Zhiyi: Lin Yutang Juan (Collected Research Materials on Contemporary Chinese Writers: Lin Yutang).[Online]

Available: http://www.linyutang.org.tw/big5/pimage/20130818104150093.pdf(November 12, 2015)

Shen, F. (1999). Six Chapters of a Floating Life. Lin Yutang (Trans.), Beijing: Foreign Language Teaching and Research Press.

Shuttleworth, M. \& Cowie, M. (2004). Dictionary of Translation Studies. Shanghai: Shanghai Foreign Language Education Press.

Toury, G. (1995). Descriptive Translation Studies and Beyond. Amsterdam: John Benjamins.

Trewin, J. C. \& Hawkes, D. (1961). Chinese Charm and Pathos. Times Literary Supplement, (3071): 26.

Wang, H. (2004). Teding Wenhua Ciyu yu Fusheng Liuji Yiben (On Lin Yutang's Translation of Chinese CultureLoaded Words in Fusheng Liuji). Foreign Language Research, (2): 104-110.

Wen, J. \& Deng, C. (2012). Guonei Fusheng Liuji Yingyi Yanjiu: Pingshu yu Jianyi (Studies of English Translations of Fusheng Liuji in China: Critical Review and Suggestions). Contemporary Research in Foreign Languages, (10): 58-62.

Williams, R. J. (2010). The Technê Whim: Lin Yutang and the Invention of the Chinese Typewriter. American Literature, 82(2): 389-419.

Yang, C.. \& Zhou, Y. (2009). Fusheng Liuji Lin Yutang Yiben zhong de Diming Yingyi Shangxi (Critical Appreciation of Lin Yutang's Translation of Place Names in Fusheng Liuji). Fujian Forum, (8): 86-87.

Zhang, N. (2004). Aikexila de Wenhua Zhuanyou Xiang Fanyi Celv Pingjie (Critical Review of Aixelá's Taxonomy of Translation Strategies for Culture-Specific Items). Chinese Translators' Journal, (1): 18-23.

Zhongguo Shekeyuan Yuyan Yanjiusuo Cidian Bianjishi (Dictionary Compilation Team of the Institute of Linguistics, Chinese Academy of Social Sciences) (2002). Xiandai Hanyu Cidian (Dictionary of Modern Chinese). Beijing: The Commercial Press.

\section{Notes}

1. All the English translations for the Chinese sources are made by the authors.

2. The Wade-Giles system for Romanizing Chinese ideograms (esp. proper nouns) was adopted in Lin's translation (e.g. "Soochow" was used instead of "Suzhou" in the pinyin system). It was gradually replaced by the pinyin system after the 1960s, but the 1999 Beijing edition retains Lin's Wade-Giles transcriptions. 
3. By definition cultural conservation strategies are roughly equivalent to "foreignizing translation", i.e. "the type of translation where a TT is produced which deliberately breaks target conventions by retaining something of the foreignness of the original" (Shuttleworth \& Cowie, 2004:59).

4. This means transferring the CSI to the target language without changing its form, hence is rarely used in translation between Chinese and English.

5. For translation between Chinese and English, transliteration is the most commonly used of this procedure (Zhang, 2004: 22).

6. Also known as "domesticating translation", i.e. the replacement of the source language CSI by a target language CSI.

7. http://baike.baidu.com/view/436085.htm

8.http://baike.baidu.com/link?url=9RMi7BwByoDZLy2DuRf1hUSWsg9UK92zqu4RjvDAaUf9fNHwM2aiScmzroIMUyUvkf_wIZ58qfMMT2UPOANpq

9. http://baike.baidu.com/view/2873232.htm

10.http://baike.baidu.com/link?url=gy2VRQ-_SCL7_tO6h0g83cVPdLw7RnJqv3YYgj7iEGWsLMNS1AvXwL1WeS2Gm8ytAs7w7Rz-vfbQ7xFC_Gzfa

11.http://baike.baidu.com/link?url=Tf275MmUTv-VUWDH7kCj5iev0ksGAlL6o3anpLBIJC3fmBNv4TN_oC4qh67SGHIGzM3NA0aA61ZuT6fDpTNoK

12. https://en.wikipedia.org/wiki/Lantingji_Xu

13.http://baike.baidu.com/link?url=4dns2YU8g9mtLtoxWKqvnSbxLq8FE9R_Z6Jf4byQVcCiY1Usv1cLK8OOYki5yiiy5oTORXuUvCy6o-BG-6-Mq

14. https://en.wikipedia.org/wiki/Fan_Zhongyan

15. http://www.etymonline.com/index.php?term=college 